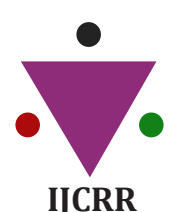

IJCRR

Section: Healthcare Sci. Journal Impact Factor: 6.1 (2018) ICV: 90.90 (2018)

(c) (i) (8)

Copyright@IJCRR

\title{
Chronicles of COVID-19 - A Brief Review
}

\section{S. Ragul Prasath¹, Keerthi Sasanka², Jothi Priya A³, Dhanraj Ganapathy}

'Saveetha Dental College, Saveetha Institute of Medical and Technical Sciences (SIMATS), Saveetha University, Chennai, India; ${ }^{2}$ Assistant Professor, Department of Prosthodontics, Saveetha Dental College, Saveetha Institute of Medical and Technical Sciences (SIMATS), Saveetha University, Chennai-600077, India; ${ }^{3}$ Assistant Professor, Department of Anatomy, Scientist, Biomedical Research Unit and Lab Animal Centre (BRULAC), Saveetha Dental College, Saveetha Institute of Medical and Technical Sciences (SIMATS), Saveetha University, Chennai, India; ${ }^{4}$ Head of Department, Department of prosthodontics, Saveetha Dental College, Saveetha Institute of Medical and Technical Sciences (SIMATS), Saveetha University, Chennai, India.

\section{ABSTRACT}

Introduction: The coronavirus disease (COVID-19) is a highly transmittable and viral infection caused by severe acute respiratory syndrome coronavirus 2 (SARS-CoV-2), which arises in Wuhan, China, and spread all around the world. The Genomic analysis shows that SARS-CoV-2 is related to severe acute respiratory syndrome-like (SARS-like) bat viruses, so bats could be the possible primary reservoir for this disease. Fractional Inactivated Poliovirus Vaccine Booster and Rotavirus Study (FIPV) is a macrophage-tropic and it is believed that it causes aberrant cytokine/chemokine expression and lymphocyte depletion, resulting in a lethal disease. Some strains of IBV, a V-coronavirus, also affect the urogenital tract of chickens causing renal disease. Infections of the reproductive tract with IBV significantly diminish egg production, causing a substantial loss in the egg production industry each year. Most adults or children with COVID-19 infection are with mild flu-like symptoms and a few patients are in critical condition and develop acute respiratory distress syndrome, respiratory failure, multiple organ failure, even death of the individuals. The intermediate source of origin and the transmission of the virus to humans is not known, the rapid human to human transfer has been confirmed widely. There is no clinically approved antiviral drug or vaccine available for COVID-19. Recombinant protein from the urban strain of SARS-CoV was administered to mice and hamsters, resulting in the production of antibodies and protection against COVID-19. Prevention is the best solution to stop the spread of coronavirus and hence the global pandemic. The current review is about the history of COVID-19.

Materials and Methods: We conducted a scoping review to draw information about the History of Coronavirus infection COVID-19. Literature Search and Inclusion/ Exclusion Criteria: The information is retrieved by searching the keywords. Sampling / Data collection was done by using search engines like Google Scholar, PubMed, Cochrane. The total number of articles searched was 30 .

Conclusion: The present medical support is only by symptomatic treatment as the vaccine is still under trials, hence preventive measures and supportive therapies are the only treatments. Most previous studies have focused on epidemiology and potential causes, whereas the current study explores the coronavirus as a whole, ranging from origin to prevention and control.

Key Words: Coronavirus, Pneumonia, Novel coronavirus 2019, 2019-nCoV, COVID-19, SARS, MERS

\section{INTRODUCTION}

The human coronaviruses history can be dated back to 1965 where Tyrrell and Bynoe found a virus that was coined as B814 which has a similar structure to the microbes that were found in human embryonic tracheal organ cultures infected with the common cold ${ }^{1,2}$. In the late 1960 s, Tyrrell and the team of virologists worked with the human strains and the number of animal viruses. This included mouse hepatitis, infectious bronchitis virus, and transmissible gastroenteritis virus. Among them, a new group of viruses with similar metabolic activities and surface structures were sampled and they were named coronavirus - Corona denoting the crownlike appearance of the surface projections in the virus and were later officially accepted as a new genus of virus ${ }^{3}$. Ongoing research is ongoing using serologic techniques has resulted in a considerable amount of information regarding the epidemiology of the human respiratory coronaviruses ${ }^{4}$. It was found that coronavirus is associated with climate, respiratory coronavirus infections occur more often in the winter and spring than in the summer ${ }^{5}$

\section{Corresponding Author:}

Dr. Keerthi Sasanka, Assistant Professor, Department of Prosthodontics, Saveetha Dental College, Saveetha Institute of Medical and Technical Sciences (SIMATS), Saveetha University, Chennai-600077, India; Email: keerthis.sdc@saveetha.com

ISSN: 2231-2196 (Print)

Received: 28.08 .2020
ISSN: $0975-5241$ (Online)

Revised: 24.09 .2020
Accepted: 22.10 .2020 


\section{METHODOLOGY}

We conducted a scoping review to draw information about the History of Coronavirus infection COVID-19.

\section{Literature Search and Inclusion/ Exclusion Criteria}

The information is retrieved by searching the keywords. Sampling / Data collection was done by using search engines like Google Scholar, Pubmed, Cochrane. The total number of articles searched was 30 . Inclusion criteria are the articles related to COVID 19, Life Cycle of Coronavirus, the origin of SARS-Cov2, prevention of COVID-19 and its treatment plan, exclusion Criteria include articles related to other categories like Awareness, Pandemic, and transmission. COVID-19 kit for testing that uses samples from oropharyngeal and nasopharyngeal part. Keywords are SARS COV 2, Global pandemic, Origin, and Evolution of coronavirus and its structure. The number of articles selected was 13; out of these the number of articles with similarity was 3 , number of articles with known concepts was 5, the number of articles with recent advances was 5 . The articles were collected, explored, and summarized.

\section{ORIGIN}

The SARS-COVID is a $\beta$-coronavirus, which is enveloped non-segmented positive-sense RNA virus (subgenus Sarbecovirus, Ortho Coronaviridae subfamily) ${ }^{6}$.Coronaviruses $(\mathrm{CoV})$ are divided into four genera, including $\alpha, \beta, \gamma, \delta \mathrm{CoV}$. $\alpha-$ and $\beta-\mathrm{CoV}$ cause infection in mammals, while $\gamma$ - and $\delta$-CoV cause infection in birds. $\beta-\mathrm{CoVs}$, SARS-CoV, and MERS-CoV are the respiratory tract infections that cause severe respiratory discomfort ${ }^{7}$ and there was $96.2 \%$ identical genome sequence in the SARS-CoV-2 when compared to the $\mathrm{CoV}$ which infects bats. Based on virus genome sequencing and evolutionary analysis shows that bat is the natural host of virus origin, and SARS- CoV-2 may be transmitted from bats via unknown intermediate hosts to humans. It is clear that SARS-CoV-2 uses the angiotensin-converting enzyme 2 (ACE2), the same receptor as SARS-CoV ${ }^{8}$. The epidemic of unknown acute respiratory tract infection broke out first in Wuhan, China, since 12 December 2019, related to a seafood market. Several studies proved that bat may be the reservoir of SARS-CoV-2 ${ }^{9}$

\section{EVIDENCE FOR NATURAL EVOLUTION}

The scientists have discovered that the Receptor binding domain (R.B.D) part of the SARS -COV-2 Spike proteins had evolved to effectively target a molecular feature on the outside of human cells called ACEZ, this is a receptor that is involved in regulating blood pressure. The SARS-COV-2 has a Spike protein which has a great binding capacity to the human cells, which can be attributed to the theory of natural selection proposed by Charles Darwin and not the product of genetic engineering. The evidence for natural selection was supported by data on SARS-COV-2's backbone): its overall molecular structure. Scientists also found that the SARSCOV-2 backbone differed substantially from those of already known Coronaviruses and mostly it resembled related viruses that are found in bats and pangolins.

These two features of the virus; the mutations in the RBD portion of the spike protein and its distinct backbone quills out laboratory manipulation as a potential origin for SARS$\mathrm{COV}-2$. Hence, the present SARS-CoV-2 is the product of natural evolution and hence ending speculation about deliberate genetic engineering. After long research on bats, researchers and scientists have found that the coronavirus is the antecedents to SARS, and also similar to hundreds of other coronaviruses which already existed within the hundreds of bats species in six continents. Coronaviruses and other virus families, it runs out, have been Co-evolving with bots for the entire span of human civilization. While the first SARS virus gets attached to the ACE-2 receptor, as well, SARS-COV-2 binds to it terracol times more efficiently. Coronaviruses majorly target the respiratory system because their ACE-2 receptors are so accessible to the outside world. Contagion is the evolutionary end goal. Coronaviruses likely have that proofreading enzyme became large - one of the largest R.N.A values in existence and they need a mechanism that maintains such a long genome's structure. The benefit of a long genome is that it has more genes and protein products a virus has, the more Opportunity we have to design specific treatments against them.

\section{CORONAVIRUS AND GENOME}

Coronaviruses are medium-sized RNA viruses and they have a very characteristic appearance of negatively stained preparations in the electron micrographs. The nucleic acid of the virus is about $30 \mathrm{~kb}$ long, positive sense, single-stranded, and polyadenylated. The RNA of the virus is the largest known viral RNA and it codes for a large polyprotein. ${ }^{10}$ The genome is packed inside a helical capsid formed by the nucleocapsid protein $(\mathrm{N})$ and further surrounded by an envelope. It is associated with the viral envelope and it has three structural proteins: They are membrane protein $(\mathrm{M})$ and the envelope protein (E) are involved in virus assembly, the spike protein $(\mathrm{S})$ mediates virus entry into host cells. There are some classes of coronaviruses that encode an envelope-associated hemagglutinin-esterase protein (HE). Among the structural proteins, the spike forms a large portion in the virus surface, giving coronaviruses the appearance of having crowns in addition to mediating virus entry ${ }^{11}$. The diameter of the envelope is $85 \mathrm{~mm}$ and the spines are $20 \mathrm{~nm}$ long. The envelope of the virus in electron micrographs appears as a distinct pair of election dense shells. The ratio of S:E:M is 20:1:300. On average, the coronary particle has 74 surface spikes. Spikes 
are of homotrimeric of the S protein, which is composed of an 8 , and $\mathrm{S} 1$ subunit. The major protein in it is the homotrimeric $\mathrm{s}$ protein which is a class 1 fusion protein that mediates the receptor binding and membrane fusion between the virus and host cell. The S, Subunit forms the head of the spine and has the receptor-binding domain (R.B.D). The S, subunit forms the stem which anchors the spike in the viral envelope and on protease activation enables fusion. The protein mainly $\mathrm{E}$ and $\mathrm{M}$ are important in forming the viral envelope and maintaining its structural shape. Inside the envelope, there is a nucleoplasmid, which is formed from the copies of the nucleoplasmid $(\mathrm{N})$ protein and is multiple, which are bound to the positive-sense single-stranded R.N.A genome in continuous beads- on a String type conformation (Figure 1).
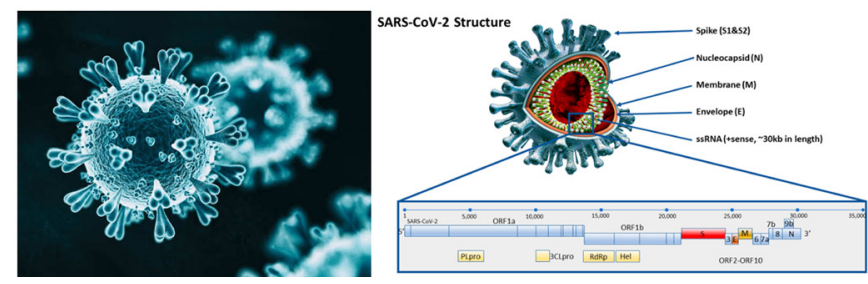

Figure 1: Coronavirus structure.

\section{LIFE CYCLE}

Infection begins with a spike protein attached to the host cell. After attachment protease of the host cell cleaves and activates the receptor attached spike protein ${ }^{12}$ depending on protease availability cleavage and activation allow the virus to enter the host cell by endocytosis or direct fusion of viral envelope ${ }^{13} \mathrm{RdRp}$ directly mediates the synthesis of negative-sense genomic RNA from positive genomic RNA molecule to this corresponds to a positive sense strand of the RNA ${ }^{14}$. The replicase transcriptase complex is also capable of genetic recombination where at least two viral genomes are present is the same infected cell ${ }^{15}$ RNA recombination appears to be a major driving force in determining genetic variability. They are capable to jump from one species to another. mRNA is the gene transcripts at the last third of the virus genome after initial overlapping. The mRNA is translated by host ribosome into structural protein and number of accessory protein this is released by cell ${ }^{16}$.

\section{PATHOGENESIS}

Fractional Inactivated Poliovirus Vaccine Booster (FIPV) is a macrophage-tropic and it is believed that it causes aberrant cytokine/chemokine expression and lymphocyte depletion, resulting in a lethal disease. Some strains of IBV, a V-coronavirus, also affect the urogenital tract of chickens causing renal disease. Infections of the reproductive tract with IBV Significantly diminish egg production, causing a substantial loss in the egg production industry each year. There is a wide available literature about the murine hepatitis virus (MHV), which commonly infects rats, this infection can affect respiratory, enteric, hepatic, and neurologic functions. This can serve as a highly useful model for understanding diseases. For instance, severe respiratory disease in susceptible AlJ and $\mathrm{C}, \mathrm{H} / \mathrm{Hey}$ mice caused by MHV-1, As5, and MHV-3 induces severe heparin's, similarly, JHMV causes encephalitis and MHV-3 induces cellular injury. SARS-COV, a group 2B-Coronavirus was identified as the causative agent of the Severe Acute Respiratory Syndrome (SARS) outbreak that occurred in 2002 in the Guang Dong province of China, It is the most severe human disease caused by any coronavirus. During the period between 2002- 2003 outbreak, approximately 8,098 cases occurred with 774 deaths, resulting in a mortality rate of $9 \%$. This rate was much higher in elderly individuals, with mortality rate cases approaching $50 \%$ in individuals over 60 years of age. ${ }^{17}$

\section{CLINICAL CHARACTERISTICS}

Acute respiratory infectious disease, COVID-19 primarily spreads through the respiratory tract droplets, respiratory secretions, and direct contact with infected person ${ }^{18}$. There are reports stating that COVID-19 was isolated from fecal swabs of a severe pneumonia patient from a case that was reported to the Fifth Affiliated Hospital, Sun Yat-Sen University, Guangdong, China ${ }^{19}$. It shows the COVID-19 present in fecal swabs and blood, and shows the possibility of multiple routes transmission of this virus. ACE2 protein presents in lung alveolar epithelial cells and enterocytes of the small intestine remarkably. The incubation period of this infection is 1-14 days, mostly 3-7 days. Most adults or children with COVID-19 infection are with mild flu-like symptoms and a few patients are in critical condition and develop acute respiratory distress syndrome, respiratory failure, multiple organ failure, even death of the individuals ${ }^{20}$. The most commonly reported Symptoms are raise in body temperature of about $102^{\circ} \mathrm{F}$, cough without expectorant, severe fatigue, pneumonia and dyspnea, where less common reported symptoms is include headache, diarrhea, halmoprysis, runny nose, and phlegm producing cough. Patients with mild symptoms were reported to recover after I week while severe cases were reported to experience progressing respiratory failure due to alveolar damage from the lungs, which may lead to death cases resulting in death were primarily middle-aged and elderly patients with pre-existing diseases (tremor surgery, cirrhosis, hypertension, coronary artery disease, diabetes, and Parkinson's disease). Case guidelines mention the symptoms such as fever, decrease in lymphocyte and the chest radiography showing the pulmonary infiltrates are required, for patients with suspected infection, the following procedures have been suggested for diagnosis: life Performing real-time fluorescence (RT-PCR ) to detect the positive nucleic acids of SARS COV 2 in sputum, throat swabs and secretions of the lower respiratory tract samples ${ }^{21}$ 


\section{TRANSMISSION}

The transmission of SARS-CoV-2 from Human-to-human is through the people within family members or people who share common vicinity where they can come into contact with asymptomatic patients or people under the incubation period. It is reported that COVID-19 affects $31.3 \%$ of patients recently travelled to Wuhan and $72.3 \%$ of patients contacting people from Wuhan among the patients of nonresidents of Wuhan ${ }^{22}$ Transmission of this virus between healthcare workers occurred in 3.8\% of COVID-19 patients. Direct contact with intermediate hosts such as animals and by consuming wild animals is the suspected route of COVID-19 transmission ${ }^{23}$.

\section{Coronavirus Transmission Cycle}

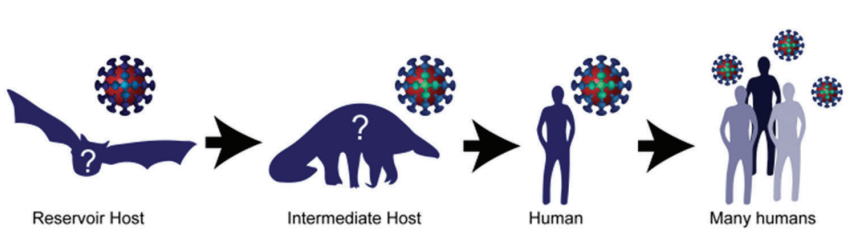

\section{TREATMENT}

The present treatment for the COVID-19 infection was only symptomatic and with the available antibiotics and antipyretics which support in the treatment by reducing the symptoms like fever, respiratory illness, and in conditions like pneumonia and steroidal treatment was advised as the effective drug or vaccine which act on the COVID-19 was under human trials, WHO also recommended the extracorporeal membrane oxygenation (ECMO) to patients with refractory hypoxemia ${ }^{24}$ Neuraminidase inhibitors (oseltamivir, peramivir, zanamivir, etc), acyclovir, and ribavirin, as well as methylprednisolone for the influenza virus, are invalid for COVID-19 and not recommended

\section{PREVENTION}

Since there are no approved treatments for this infection, prevention is better. Several properties of this virus make prevention difficult, non-specific features of the disease, the infectivity before the onset of symptoms in the incubation period, easy transmission from asymptomatic people, the long incubation period for this disease, tropism for mucosal surfaces such as the conjunctiva, prolonged duration illness and transmission of the virus even after clinical recovery. Isolation of confirmed or suspected cases even mild illness at home is recommended for effective prevention of this disease $^{25}$. The fresh air/machines that bring fresh air at home should be good; there should be a provision at sunlight in the home which allows for the destruction of viruses. It is mandatory that patients must don surgical masks and keep themselves /something clean, which is implied to the caregivers when in the same room with a patient and use keeping themselves/something clean every 15-20 min. Prevention and control, the success plans/ways of reaching goals and methods are reported at three levels. They are national level, Case related population level, and general population level 26,27 . Under this policy, medical students of various institutions can adopt isolation treatment and observation protocols to prevent nosocomial infection. in the month of January 2020, the protocols required for the prevention and control of the spread of the infections were issued by the National Health Commission through big isolation and big disinfection policy during the Chinese spring festival $\mathrm{Na}$ tional level have also been issued with targeted measures for rural areas and the elderly population. Several public health measures that may prevent or slow down the transmission of the coronavirus were introduced; these include case isolation, identification, and follow-up Contacts, environmental disinfection, and use of personal protective equipment ${ }^{28,29}$.

\section{VACCINES FOR SARS COV-2}

There is no available vaccine against COVID-19, while previous vaccines or strategies used against SARS-CoV can be effective for this COVID-19. Recombinant protein from the Urbani strain of SARS-CoV was administered to mice and hamsters, resulting in the production of antibodies and protection against COVID-19. The development of the vaccines against SARS-CoV-2 infection was still under the Clinical trials, which was in phase 1 trial, soon mRNA based vaccine's sample (prepared by Stermirna Therape Therapeutics) will be available. GeoVax-BravoVax is working to develop a Modified Vaccinia Ankara (MVA) based vaccine ${ }^{30}$.

This review applied a rigorous search strategy to retrieve relevant articles according to research objectives. This research summarizes scientific foundations, history, origin, evolution, Life cycle, pathogenesis, and prevention and control of Coronavirus spread (Global pandemic).our study only focuses on the articles published either in English / Chinese during the outbreak period. This study will provide some evidence for future Study and control.

\section{CONCLUSION}

The present medical support is only by symptomatic treatment as the vaccine is still under trials, hence preventive measures and supportive therapies are the only treatments. Most previous studies have focused on epidemiology and potential causes, whereas the current study explores the coronavirus as a whole, ranging from origin to prevention and control implicating the etiology and pathogenicity which can be used for further epidemiological studies. 


\section{Author Contributions}

S.Ragul Prasath, carried out the study by collecting the data and drafted The manuscript after performing the necessary statistical analysis. Dr. L. Keerthi Sasanka aided in conception of the topic, has participated in the study design, statistical analysis and supervised in preparation of the manuscript. Dr. Jothi Priya.A, Dr. Dhanraj Ganapathy have participated in the study design and has coordinated in developing the manuscript. All the authors have discussed the results among themselves and contributed to the final manuscript.

\section{ACKNOWLEDGMENTS}

This research was done under the supervision of the Department of research at Saveetha Dental College and Hospital. We sincerely show gratitude to the corresponding guide who provided insight and expertise that greatly assisted the research.

\section{Conflict of Interest}

None declared.

\section{Financial Support}

The author(s) received no financial support for the research, authorship, and/or publication of this article.

\section{REFERENCES}

1. Tyrrell DA, Bynoe ML. Cultivation of viruses from a high proportion of patients with colds. Lancet. 1966:76-77.

2. Goryunova AG, Alekseeva AK, Zalkind SY. Organ cultures of the respiratory tract of the human embryo. Bulletin of Experimental Biology and Medicine. 1970 May 1;69(5):583-5.

3. Tyrrell DA, Almeida JD, Cunningham CH, Dowdle WR, Hofstad MS, McIntosh K, Tajima M, Zakstelskaya LY, Easterday BC, Kapikian A, Bingham RW. Coronaviridae. Intervirology. 1975 Jul;5(1-2):76.

4. David, David, Jothi Priya A, et al. Physical Fitness among the Dental Physician, Dental Undergraduates and Postgraduates Students. Indian Journal of Public Health Research \& Development 2019; 10: 223.

5. Mcintosh K, Kapikian AZ, Turner HC, et al. Seroepidemiologic studies of coronavirus infection in adults and children. American Journal of Epidemiology 1970; 91: 585-592.

6. Zhu N, Zhang D, Wang W, et al. A Novel Coronavirus from Patients with Pneumonia in China, 2019. New England Journal of Medicine 2020; 382: 727-733.

7. Yin Y, Wunderink RG. MERS, SARS and other coronaviruses as causes of pneumonia. Respirology 2018; 23: 130-137.

8. Zhou P, Yang X-L, Wang X-G, et al. A pneumonia outbreak associated with a new coronavirus of probable bat origin. Nature 2020; 579: 270-273.

9. Perlman S, Holmes K. The Nidoviruses: Toward Control of SARS and other Nidovirus Diseases. Springer Science \& Business Media, 2007.

10. R GD, Sethu G. Evaluation of Adenoids by Oronasal and Nasal Spirometry. Asian Journal of Pharmaceutical and Clinical Research 2018; 11: 272.
11. Kahn JS, McIntosh K. History and Recent Advances in Coronavirus Discovery. The Pediatric Infectious Disease Journal 2005; 24: S223-S227.

12. Harsha L, Priya J, Shah KK, et al. Systemic Approach to Management of Neonatal Jaundice and Prevention of Kernicterus. Research Journal of Pharmacy and Technology 2015; 8: 1087.

13. Fehr AR, Perlman S. Coronaviruses: An Overview of Their Replication and Pathogenesis. Coronaviruses 2015; 1-23.

14. Shaffer T. Book Review: Doing Family Therapy: Craft and Creativity in Clinical Practice.(2007). Robert Taibbi (Ed.), New York: The Guilford Press, 278 pp., US \$26.00, ISBN\# 978-159385-477-5. The Family Journal. 2009 Jul;17(3):296-.

15. Fathima F, Preetha P. EVALUATION OF THYROID FUNCTION TEST IN OBESE PATIENTS. Asian Journal of Pharmaceutical and Clinical Research 2016; 9: 353.

16. Li F. Structure, Function, and Evolution of Coronavirus Spike Proteins. Annual Review of Virology 2016; 3: 237-261.

17. Parveen S, Jain S. Pathophysiologic Enigma of COVID-19 Pandemic with Clinical Correlates. International Journal of Current Research and Review 2020; 12: 33-37.

18. Li Q, Guan X, Wu P, et al. Early Transmission Dynamics in Wuhan, China, of Novel Coronavirus-Infected Pneumonia. N Engl J Med 2020; 382: 1199-1207.

19. Selvan SR, Ganapathy D. Efficacy of fifth generation cephalosporins against methicillin-resistant Staphylococcus aureus-A review. Research Journal of Pharmacy and Technology 2016; 9: 1815.

20. Ariga P, Nallaswamy D, Jain AR, et al. Determination of Correlation of Width of Maxillary Anterior Teeth using Extraoral and Intraoral Factors in Indian Population: A Systematic Review. World Journal of Dentistry 2018; 9: 68-75.

21. Ashok V, Nallaswamy D, Benazir Begum S, et al. Lip Bumper Prosthesis for an Acromegaly Patient: A Clinical Report. The Journal of Indian Prosthodontic Society 2014; 14: 279-282.

22. Ganapathy DM, Kannan A, Venugopalan S. Effect of Coated Surfaces influencing Screw Loosening in Implants: A Systematic Review and Meta-analysis. World Journal of Dentistry 2017; 8: 496-502.

23. Venugopalan S, Ariga P, Aggarwal P, et al. Magnetically retained silicone facial prosthesis. Niger J Clin Pract 2014; 17: 260-264.

24. Jyothi S, Robin PK, Ganapathy D, et al. Periodontal Health Status of Three Different Groups Wearing Temporary Partial Denture. Research Journal of Pharmacy and Technology 2017; 10: 4339.

25. Ashok V, Suvitha S. Awareness of all ceramic restoration in rural population. Research Journal of Pharmacy and Technology 2016; 9: 1691.

26. Ganapathy D, Sathyamoorthy A, Ranganathan H, Murthykumar $\mathrm{K}$. Effect of resin bonded luting agents influencing marginal discrepancy in all ceramic complete veneer crowns. Journal of Clinical and Diagnostic Research: JCDR. 2016 Dec;10(12):ZC67.

27. Basha FYS, Ganapathy D, Venugopalan S. Oral Hygiene Status among Pregnant Women. Research Journal of Pharmacy and Technology 2018; 11: 3099.

28. Ajay R, Suma K, Ali S, et al. Effect of surface modifications on the retention of cement-retained implant crowns under fatigue loads: An In vitro study. Journal of Pharmacy And Bioallied Sciences 2017; 9: 154.

29. Duraisamy R, Krishnan CS, Ramasubramanian H, et al. Compatibility of Nonoriginal Abutments With Implants: Evaluation of Microgap at the Implant-Abutment Interface, With Original and Nonoriginal Abutments. Implant Dent 2019; 28: 289-295.

30. Kannan A, Venugopalan S. A systematic review on the effect of use of impregnated retraction cords on gingiva. Research Journal of Pharmacy and Technology 2018; 11: 2121. 